\title{
Vienna accord on remote sensing
}

Conference calls for bigger UN role

\section{Vienna}

New and expanded space-related activities, recommended to the United Nations by the Unispace- 82 conference which ended last Saturday, should cost the United Nations \$3.2 million annually almost four times the 1980-81 budget of the existing Outer Space Affairs Division of the UN Secretariat. These activities, the conference proposed, should be funded voluntarily by the member nations, and the UN General Assembly should rearrange its budget so that the increase in personnel costs may be absorbed within the available resources.

The proposed activities are largely information related, including consultancy services to assist developing countries in selecting space technology systems, study tours, seminars, and training fellowships, the creation of an international space information service, expansion of the existing space library and the establishment of a regular newsletter on space.

The need for such services became abundantly clear during the two weeks of Unispace-82; remote sensing has been constantly hailed as the answer to environmental and resource problems, and a bewilderingly large range of systems was on display for developing countries shopping for hardware or know-how. Yet the suppliers of these products were often first to admit that their data are simply not reaching those who most need the information. One representative of the UK Natural Environmental Research Council quoted the case of a remote sensing programme which identified icebergs heading directly for a Canadian off-shore oil-rig - with no organizational framework through which a warning could be transmitted to the rig at risk.

The conference report called for the formulation of international principles on satellite remote sensing which would allow the "sensed" state "timely and nondiscriminatory access under reasonable conditions" to primary data relating to its territory.

The conference also expressed "real concern" over the approaching saturation of the geostationary orbit with communications satellites in certain frequency bands. Research into ways of facilitating the closer siting of satellites is "imperative", and the feasibility of using highly elliptical orbits for communications satellites should be re-examined. The International Telecommunications Union was recommended to consider introducing into its future regulations a clause stating that a satellite owner was responsible for removing its hardware from orbit when it became inoperable.

Similarly, although the conference urged member countries to examine the feasibility of direct television broadcasting satellites for education in remote rural areas, it also urged them to consider the possibility of international or regional satellite space segments, shared by neighbouring countries.

In general, the conference confined itself to the specifics of space technology and its applications but there was also a full

\section{Few winners in Australian budget}

\section{Sydney}

The Australian government's latest budget, framed amid growing speculation about an early election, once again cuts back on funding for most areas of scientific research. The budget, released last week, was built around tax cuts and other handouts for the middle income earners. The government proved once again that they see very few votes in research funding.

Australia spends less than 1 per cent of gross domestic product on research, considerably less than most Western countries. The government provides about 70 per cent of this funding, which is an unusually large proportion by world standards. This year over half this money will go to the Commonwealth Scientific and Industrial Research Organization (CSIRO) and the rest to the other government agencies and the universities.

One of the few bright spots in the budget is the re-allocation of A $\$ 49$ million ( $\$ 27$ million) to a scheme that favours research projects with product-oriented goals. This

\section{Canada's array poised}

While Australian radioastronomers have just received the go ahead for their long baseline array of telescopes (see above) the fate of a Canadian counterpart is still in the balance.

The Canadian Long Baseline Array (CLBA) has already been approved in principle by the National Research Council (NRC) which has selected it over several competing big-science projects, such as the Canadian high energy electron ring and Starlab. A final proposal for the CLBA will probably be approved by NRC in September. The economic development committee of the Canadian cabinet will then have 'o decide whether it can afford the Canadian $\$ 70$ million needed to construct CLBA - with $\$ 6.5$ million per year running costs - in the midst of a recession. discussion of the problem of preserving peace in space. After the three main committees of the conference had failed to reach consensus on this issue, Dr Willibald Pahr, the Austrian foreign secretary and president of the conference, convened a 15-member drafting group, called the "Friends of the president" which represented all regional groups and which finally, and with the conference in extra time, found an acceptable consensus wording calling on all nations, "in particular those with major space capabilities" to "contribute actively to preventing an arms race in outer space"

Vera Rich

re-allocation came as a surprise because the scheme, funded under the Industrial Research and Incentives Act, was left up in the air last year when its budget was frozen after only A $\$ 24$ million was spent.

In the budget, basic research in universities has been given A\$19 million, around 4 per cent less in real terms than in 1981. This continues the steady decline which has gone on since 1975 . The funds are channelled through the Australian Research Grants Scheme (ARGS) which now contributes only 15 per cent of the total national research spending compared with 24 per cent in 1975. If ARGS uses its reduced budget to maintain the top research groups, it will be unable to support about 100 projects that would otherwise have been accepted, according to Professor Max Brennan, chairman of the committee administering the scheme.

But there were some winners in the area of basic research. In astronomy, prior to the budget, two proposals were vying for patronage. One was the radioastronomers'

The current proposal for CLBA calls for eight 32-metre dishes spread from British Colombia across to Newfoundland and one smaller dish in the North West Territories. Thomas H. Legg, the originator of the project, says the CLBA could be operating within four to five years of approval. The schedule is important, for the United States is planning its own very long baseline array that would stretch across the continent and include sites in Hawaii and Alaska. A proposal for building the system has been submitted to the US National Science Foundation (Nature 12 August, p.596) but whether it will be included in the US budget for fiscal 1984 is anybody's guess. There is a debate about the need for two separate systems of this size and both the Canadian and the US sides have thought about a possible link but nothing concrete has yet been proposed. 